\title{
QUANTIFICATION OF THE URANIUM CONCENTRATION IN HUMAN URINE BY INDUCTIVELY COUPLED PLASMA-SECTOR FIELD MASS SPECTROMETRY (ICP-SFMS)
}

Héctor Hernández-Mendoza*

Departamento de Química, Instituto Nacional de Investigaciones Nucleares, Carretera México-Toluca s/n, 52750 La Marquesa Ocoyoacac, México

Estefanía Conde, Marta Fernández and Abel Yllera

Centro de Investigaciones Energéticas, Medioambientales y Tecnológicas (CIEMAT) Av. Complutense 22, Madrid 28040, Spain

Recebido em 23/5/12; aceito em 19/12/12; publicado na web em 24/5/13

\begin{abstract}
In this study, the validation of a method for analyzing the uranium (U) concentration in human urine samples by inductively coupled plasma-sector field mass spectrometry (ICP-SFMS) was conducted. PROCORAD (the Association for the Promotion of Quality Control in Radiotoxicological Analysis) provided two urine samples spiked with unknown contents of $U$ (Sample A = 33.6 \pm 1.0 $\mu \mathrm{g} / \mathrm{L}$ and Sample $\mathrm{B}=3.3 \pm 0.1 \mu \mathrm{g} / \mathrm{L}$ ) and one unspiked sample as a blank. The analyses were directly performed on the diluted urine samples (dilution factor $=1: 20$ ) in $5 \% \mathrm{v} / \mathrm{v} \mathrm{HNO}_{3}$. The results obtained by ICP-SFMS corresponded well with the reference values, and the limits of detection were ${ }^{235} \mathrm{U}=0.049 \times 10^{-3} \mu \mathrm{g} / \mathrm{L}$ and ${ }^{238} \mathrm{U}=7.37 \times 10^{-3} \mu \mathrm{g} / \mathrm{L}$. The ICP-SFMS technique has been shown to be successful in the analysis of the $\mathrm{U}$ concentration in human urine samples and for the quantification of isotopic ratios.
\end{abstract}

Keywords: uranium; urine; ICP-MS.

\section{INTRODUCTION}

Uranium $(\mathrm{U})$ is a naturally occurring radioactive element, which is found in varying amounts in the environment (soil: $\sim 1 \times 10^{3}-5 \times$ $10^{3} \mu \mathrm{g} / \mathrm{Kg}$; water: $\sim 0.1-5 \mu \mathrm{g} / \mathrm{L}$ ), and the anthropogenic addition to this natural background is insignificant, except near point sources of $U$ release. Natural $U$ consists of three radioactive isotopes with the following relative isotopic abundances: ${ }^{234} \mathrm{U}(0.00515 \%),{ }^{235} \mathrm{U}$ $(0.71192 \%)$, and ${ }^{238} \mathrm{U}(99.282 \%) .{ }^{1}$ Regarding toxicity for humans, the aerosol exposure pathway is critical for hazard assessment in which inhalation exposure to relatively insoluble $\mathrm{U}$ oxide particles represents a potentially long-term reservoir of internal alpha decay activity that can cause cell damage. ${ }^{2}$ Although variable quantities of either soluble or insoluble natural $U$ are regularly ingested by consumption of food and drink, little of this $\mathrm{U}$ is absorbed into the blood stream. ${ }^{3}$ According to the World Health Organization, ${ }^{4}$ around $98 \%$ of $\mathrm{U}$ entering the body via ingestion is not absorbed, but is eliminated via feces. Typical gut absorption rates for $\mathrm{U}$ in food and water are around $2 \%$ for soluble and around $0.2 \%$ for insoluble $U$ compounds. For some soluble forms, more than $20 \%$ of the inhaled material can be absorbed into the blood. Of the $\mathrm{U}$ that is absorbed into the blood, approximately $70 \%$ will be filtered by the kidneys and excreted in the urine within $24 \mathrm{~h}$; this amount increases to $90 \%$ within a few days after exposure. Average annual intakes of $U$ by adults are estimated to be around $5 \times 10^{2} \mu \mathrm{g}$ by ingestion of food and water and $0.6 \mu \mathrm{g}$ by breathing air. ${ }^{5}$

The human body contains, on average, approximately $90 \mu \mathrm{g}$ of $\mathrm{U}$ from normal intakes of water, food, and air. Around $66 \%$ is found in the skeleton, $16 \%$ in the liver, $8 \%$ in the kidneys, and $10 \%$ in other tissues. ${ }^{5,6} \mathrm{U}$ excretion in feces and urine for non-exposed subjects is typically on the order of some nanogram per day, ${ }^{7}$ but it may depend on the dietary habits. ${ }^{1}$

In the case of professionally exposed staff (such as workers in nuclear power plants, military industry, $U$ mining, and scientific research), the occupational monitoring of workers exposed to the risk of

*e-mail: hector.hernandez520@gmail.com contamination in the workplace is imperative. ${ }^{8}$ The routine bioassay of human urine samples using radiometric techniques normally requires preconcentration and purification of the radionuclides prior to measurements. ${ }^{9}$ As a result, these procedures are very time consuming, and this represents a significant impediment in emergency situations. Moreover, the preconcentration and chemical separation processes could add varying amounts of $U$ owing to the presence of naturally occurring $U$ in the reagents. However, this contribution could be minimized by sub-boiling distillation of the acids used during the preparation of the samples (which is a common practice in mass spectrometry (MS) analysis).

MS techniques ${ }^{10}$ such as inductively coupled plasma mass spectrometry (ICP-MS), thermal ionization mass spectrometry (TIMS), and accelerator mass spectrometry (AMS) are applied to obtain accurate and precise isotopic information of actinides in several matrices. Although both TIMS and AMS provide low limit of detection (LOD), sample preparation is very time consuming compared with that for ICP-MS. The drawback of the AMS technique is that it requires higher operation and maintenance costs than ICP-MS. The ICP-MS technology has been developing for more than 30 years by building and augmenting instrumentation, such as nebulizers, ${ }^{11}$ detectors, ${ }^{12}$ coupling with separation techniques and laser ablation, ${ }^{13,14}$ and electronic devices ${ }^{15}$ and sample introduction systems, ${ }^{11}$ and has been extensively used in a wide variety of applications. More interesting information about the fundamentals, instrumentation, and applications of ICP-MS can also be found in a recent critical review reported by Jakubowski et al. ${ }^{16,17}$

Among the various applications of ICP-MS, the analysis of longlived radionuclides at ultra-trace concentrations for environmental monitoring or human bio-monitoring is a research field of special interest. Recently, Fukushima Daiichi's events have highlighted the need for rapid methods for analyzing in different matrices to ensure the safety of the population (analysis of water, air, and food) and health (bioassays to determine the levels of incorporation of radioisotopes in the body). In this sense, analytical techniques based on ICP-MS have made significant progress in the determination of actinides in human urine at ultra-trace concentrations with high productivity and extremely high sensitivity. In the case of inductively coupled plasma-quadrupole mass spectrometry (ICP-QMS), its main features 
can be shortly summarized as follows ${ }^{15}$ : a) $90 \%$ of the elements can be measured, b) around 50 elements are detectable in concentrations as low as $1.0 \times 10^{-3} \mu \mathrm{g} / \mathrm{L}, \mathrm{c}$ ) isotopic ratios can be determined, d) it offers high performance for routine analysis, and e) possesses a large dynamic range. However, polyatomic interferences and isotopic ratio uncertainty are the main drawbacks of this technique. The application of ICP-SFMS with a single ion collector has been demonstrated as a useful alternative for solving some of the problems involving polyatomic interferences during measurements, and as a powerful tool for the analysis of actinides in biological samples at ultra-trace concentrations. ${ }^{18}$ The main characteristics of this technique are its extremely high sensitivity, precision and accuracy, and an extended dynamic range up to $\sim 10^{12} .{ }^{15}$ However, multiple ion collector instruments are often better suited than ICP-SFMS for isotopic ratio determination because the isotope measurements are simultaneously performed, minimizing the influence of the counting dead time and increasing the precision and accuracy for the analysis of isotopic ratios. ${ }^{19}$ Therefore, the application of ICP-MS techniques would provide significant support to dosimetry laboratories, which use radiometric techniques based on alpha spectrometry (AS) for the routine analysis of actinides in urine with the aim of providing comprehensive information to estimate dosages incorporated into the human body. ${ }^{20,21}$

This study aims to validate a method for the determination of the $\mathrm{U}$ concentration in human urine samples by ICP-SFMS. The method employed was based on urine dilution followed by direct analysis and was validated by the participation with PROCORAD (the Association for the Promotion of Quality Control in Radiotoxicological Analysis) through the intercomparison exercise conducted in 2010. In addition, second analysis of samples was also carried out with ICP-QMS, and the results obtained in analysis of $U$ were compared with those of ICP-SFMS.

\section{EXPERIMENTAL}

\section{Instrumentation}

Two different mass spectrometers were employed for measuring of U isotopes: an ICP-QMS (X-Series 2, Thermo Scientific, Bremen, Germany) and an ICP-SFMS (Element XR, Thermo Scientific, Bremen Germany). A Meinhard nebulizer with a Scott (Ryton) spray chamber (Elemental Scientific Inc., USA) was used for ICP-QMS, whereas a microflow nebulizer PFA-100 coupled to a Twister with a Helix $50 \mathrm{~mL}$ cyclonic borosilicate glass spray chamber (Elemental Scientific Inc., USA) was employed for ICP-SFMS. The torch of the ICP-SFMS instrument (Elemental Scientific Inc., USA) was shielded with a grounded platinum electrode (GuardElectrodeTM, Thermo Scientific).

\section{Materials and reagents}

Two certified solutions of ${ }^{235} \mathrm{U}$ (IRMM-050) and ${ }^{238} \mathrm{U}$ (IRMM053) were supplied by the Institute for Reference Materials and Measurements (GEEL, Belgium). The standards were diluted with $5 \mathrm{~mol} / \mathrm{L}$ of $\mathrm{HNO}_{3}$ to obtain stock solutions with a concentration of $1.182 \times 10^{-4} \mu \mathrm{g} / \mathrm{L}$ of ${ }^{235} \mathrm{U}$ and $1.175 \times 10^{-4} \mu \mathrm{g} / \mathrm{L}$ of ${ }^{238} \mathrm{U}$. An aliquot of $10 \mu \mathrm{g} / \mathrm{L}$ of a Lu external standard solution (Merck, Germany) was used during the measurements for monitoring the instrumental stability. Instrumental mass calibration of ICP-SFMS was performed using a certified multi-element solution XXIII (Ba, B, Co, Fe, Ga, In, K, Li, Lu, Na, Rh, Sc, Y, Tl, and U) from Merck (Germany). This solution had a concentration of $1.1 \pm 0.2 \mu \mathrm{g} / \mathrm{L}$ of natural $\mathrm{U}$. The mass calibration of ICP-QMS was carried out with a certified multi-element solution Tune A (As, Ba, Be, Bi, Ce, Co, In, Li, $\mathrm{Ni}, \mathrm{Pb}$, and $\mathrm{U}$ ) supplied by Analytika Ltd. (Czech Republic). This solution has a concentration of $10.0 \pm 2.0 \mu \mathrm{g} / \mathrm{L}$ of natural $\mathrm{U}$. Indium was used as an internal standard in both cases (ICP-SFMS: $1.0 \pm$ $0.2 \mu \mathrm{g} / \mathrm{L}$ and ICP-QMS: $10.5 \pm 2.0 \mu \mathrm{g} / \mathrm{L})$. The remaining salts and solutions were prepared using analytical grade reagents from Merck (Germany). High purity water (> $18 \mathrm{M} \Omega / \mathrm{cm}$ ) was obtained from a Milli-Q Element A10 Century (Millipore Ibérica, Spain). Nitric acid was purified by distillation in a Milestone Duopur (Milestone s.r.l., Italy) sub-boiling system. Certified Ar gas (99.999\%) was supplied by Air Liquide España. The U measurements were carried out in a clean room laboratory (ISO 6 class) at $24 \pm 1{ }^{\circ} \mathrm{C}$.

\section{Sample preparation}

Three $0.5 \mathrm{~L}$ human urine samples were received from PROCORAD. Two of them of unknown U concentrations (Sample A having a high concentration and sample B having a low concentration) and one unspiked sample for background measurements (sample C) were used. Sample aliquots were diluted with $5 \%$ v/v $\mathrm{HNO}_{3}$ (dilution factor of 1:20; 10 replicates). The external calibration method was employed for $U$ quantification (Figure 1). Calibration curves were prepared by addition of known quantities of ${ }^{235} \mathrm{U}$ and ${ }^{238} \mathrm{U}$ to sample $\mathrm{C}$.

\section{RESULTS AND DISCUSSIONS}

In Spain, the Research Center of Environment and Energy and Technology (CIEMAT) is responsible for monitoring people who are professionally exposed to ionizing radiation and for monitoring environmental radiation levels. CIEMAT's laboratories undergo continued accreditation and certification. The accreditation of bioassay analyses of actinides notably requires intercomparison tests between laboratories. PROCORAD is one of the most important providers in this field. The organization provides an opportunity to compare and contrast radiochemistry methods and metrology for the in vitro analysis of urine and feces. This focus, the development of new techniques such as ICP-MS, AS, and laser spectrofluorimetry, have been important for development of protocols of standardization and have made it possible to compare the effectiveness of these protocols with respect to radiation protection monitoring, both in routine and special situations. In intercomparison, the participants receive two urine samples spiked with unknown contents of $U$ and one unspiked sample as a blank. The nature of the intercomparison process therefore affects the reporting process such that the LOD, flexibility, repeatability, reproducibility, and isotopic quantification are considered to be the main criteria.

\section{Optimization of parameters for the measurement of $U$ isotopes}

The optimized instrumental conditions are summarized in Table 1. In the case of ICP-SFMS, the optimization for U isotopes was attained by tuning the instrument with the certified multi-element solution XXIII $\left({ }^{235} \mathrm{U}=(10.2 \pm 0.2) \times 10^{3} \mathrm{cps} ;{ }^{238} \mathrm{U}=(1.38 \pm 0.03)\right.$ $\times 10^{6} \mathrm{cps}$ ), with a $\mathrm{U}$ oxide content in the plasma less than $5 \%$. The ICP-QMS instrument was tuned with the Tune A solution giving a ${ }^{238} \mathrm{U}$ peak at around $(8.0 \pm 0.2) \times 10^{4} \mathrm{cps}$.

\section{LOD}

Figure 1 shows the calibration curves for ${ }^{235} \mathrm{U}$ and ${ }^{238} \mathrm{U}$ in urine samples. In the case of ICP-SFMS, a reasonably good linearity was obtained in the range from $1.0 \times 10^{-6} \mu \mathrm{g} / \mathrm{L}$ to $2.5 \times 10^{-2} \mu \mathrm{g} / \mathrm{L}\left({ }^{235} \mathrm{U}\right)$ and $5.0 \times 10^{-6} \mu \mathrm{g} / \mathrm{L}$ to $4 \mu \mathrm{g} / \mathrm{L}\left({ }^{238} \mathrm{U}\right)$. For ICP-QMS, the calibration curve for ${ }^{238} \mathrm{U}$ also shows very good linearity in the range from $1.0 \times 10^{-3} \mu \mathrm{g} / \mathrm{L}$ to $5 \mu \mathrm{g} / \mathrm{L}$. LOD calculations of $\mathrm{U}$, shown in Table 2, 

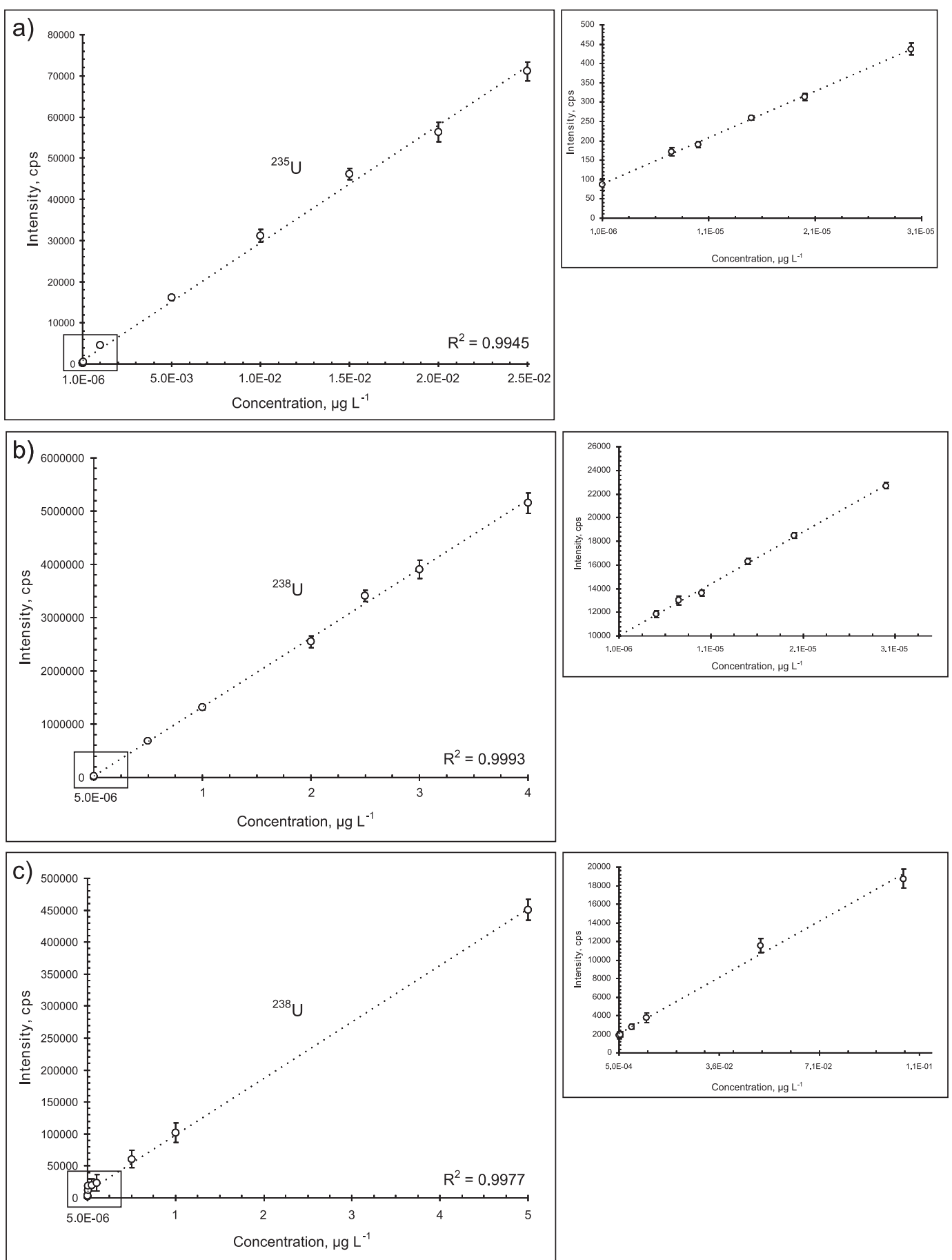

Figure 1. Calibration curves for U isotopes; a) ICP-SFMS calibration curve for ${ }^{235} U$; b) ICP-SFMS calibration curve for ${ }^{238} U$; c) ICP-QMS calibration curve for ${ }^{238} \mathrm{U}$. Due to its very low concentration, the ${ }^{235} \mathrm{U}$ isotope was not detected by ICP-QMS

were calculated on the basis of the $3 \sigma$ value of blank measurements (for $\mathrm{n}=10$ ) from Equation 1:

$$
L O D=3 \times \sigma_{B} \times D F \times V,
$$

where the dilution factor (DF) was 1:20 and the total volume of the urine samples $(\mathrm{V})$ was $500 \mathrm{~mL}$.

\section{Validation of the method}

The method proposed with ICP-SFMS has been validated by performing blind analyses of standardized urine samples during an international intercomparison exercise (PROCORAD 2010). The results of the reference materials are plotted in Figure 2. The experimental results indicate that the procedure performed can be applied to both ICP-MS instruments, although those obtained with ICP-SFMS showed greater accuracy and precision in the measured $\mathrm{U}$ values. Therefore, the results accorded better with the reference values in comparison with those provided by ICP-QMS. The results of the quantification of the ${ }^{238} \mathrm{U}$ concentration in human urine samples conducted for the PROCORAD intercomparison of 2010 are summarized in Table 3. The results obtained in the analysis of ${ }^{238} \mathrm{U}$ by ICP-QMS were not particularly accurate owing to the effect of the sample matrix. Moreover, the ${ }^{235} \mathrm{U}$ concentration could not be 
Table 1. ICP-SFMS and ICP-QMS optimized instrumental conditions for the measurement of U isotopes

\begin{tabular}{llll}
\hline & ICP-SFMS & & ICP-QMS \\
\hline Solution uptake rate & $0.5 \mathrm{~mL} \mathrm{~min}^{-1}$ & Solution uptake rate & $0.5 \mathrm{~mL} \mathrm{~min}^{-1}$ \\
RF power & $1375 \mathrm{~W}$ & RF power & $900 \mathrm{~W}$ \\
Cool gas flow rate & $16.51 \mathrm{~L} \mathrm{~min}^{-1}$ & Plasma gas flor rate & $15.02 \mathrm{~L} \mathrm{~min}^{-1}$ \\
Auxiliary gas flow rate & $0.74 \mathrm{~L} \mathrm{~min}^{-1}$ & Auxiliary gas flow rate & $0.68 \mathrm{~L} \mathrm{~min}^{-1}$ \\
Nebulizer gas flow rate & $1.194 \mathrm{~L} \mathrm{~min}^{-1}$ & Nebulizer gas flow rate & $0.79 \mathrm{~L} \mathrm{~min}^{-1}$ \\
Ion extraction lens potential & $-2000 \mathrm{~V}$ & Isotope & ${ }^{115} \mathrm{In} \mathrm{and}{ }^{238} \mathrm{U}$ \\
Mass resolution $(\mathrm{m} / \Delta \mathrm{m})$ & 300 & Reading per replicate & 300 \\
Isotope & $115 \mathrm{In},{ }^{235} \mathrm{U}$ and ${ }^{238} \mathrm{U}$ & Number of replicates & 3 \\
Samples per peak & 100 & Total analysis time per sample & 5 min \\
Settling time & $10 \mathrm{~ms}$ & Scan mode & Peak hop transient \\
Sample time & $10 \mathrm{~ms}$ & Detection mode & Dual- pulse and analog \\
Points per width & 10 & Resolution & $10 \%$ peak integrated maximum \\
Peak shift & 1.0 & Integration type & Average \\
Mass window & $20 \%$ & Sample cone & Nickel $1 \mathrm{~mm}^{2}$ \\
Integration window & $80 \%$ & skimmer cone & Nickel $0.9 \mathrm{~mm}$ \\
Scan type & E-Scan & Spray chamber & Scott (Ryton) \\
Detection mode & Triple & Nebulizer & Meinhard $0.1 \mathrm{~mL} \mathrm{~min}{ }^{-1}$ \\
Total analysis time per sample & $5 \mathrm{~min}$ & &
\end{tabular}

Table 2. LOD of U in human urine samples by ICP-SFMS and ICP-QMS

\begin{tabular}{ccc}
\hline \multicolumn{2}{c}{ ICP-SFMS } & ICP-QMS \\
\hline${ }^{235} \mathrm{U} \mu \mathrm{g} \mathrm{L}^{-1}$ & ${ }^{238} \mathrm{U} \mu \mathrm{g} \mathrm{L}^{-1}$ & ${ }^{238} \mathrm{U} \mu \mathrm{g} \mathrm{L}^{-1}$ \\
$0.049 \times 10^{-3}$ & $7.37 \times 10^{-3}$ & $1.02 \times 10^{-2}$ \\
\hline
\end{tabular}

determined by ICP-QMS because of the low levels of ${ }^{235} \mathrm{U}$ contained within the samples. On the other hand, ICP-SFMS was also used to measure the ${ }^{235} \mathrm{U}$ content in both urine samples by using the external calibration method, and the results were Sample A $=(5.43 \pm 0.22)$ $\times 10^{-2} \mu \mathrm{g}$ of ${ }^{235} \mathrm{U}$ and Sample B $=(4.59 \pm 0.58) \times 10^{-3} \mu \mathrm{g}$ of ${ }^{235} \mathrm{U}$. Finally, this study illustrated the capacity of SF-ICP-MS for the determination of isotopic ratios of $U$ in urine samples (A and $B$ ). The results obtained for the $\left({ }^{235} \mathrm{U} /{ }^{238} \mathrm{U}\right)$ isotopic ratios of the PROCORAD urine samples are given in Figure 3. Furthermore, the analysis of isotopic ratios of $\mathrm{U}$ for Samples A and B has not showed significant differences, and the results verified that the urine samples contained $\mathrm{U}$ levels isotopically consistent with the composition of natural $\mathrm{U}$.

Table 3. Summary of results for ${ }^{238} U$ in human urine samples during the PROCORAD 2010 exercise

\begin{tabular}{cccc}
\hline Sample & $\begin{array}{c}\text { ICP-SFMS } \\
\text { U/sample }(\mu \mathrm{g})\end{array}$ & $\begin{array}{c}\text { ICP-QMS } \\
\text { U/sample }(\mu \mathrm{g})\end{array}$ & $\begin{array}{c}\text { Target value } \\
\text { U/sample }(\mu \mathrm{g})\end{array}$ \\
\hline A & $17.7 \pm 0.8$ & $19.4 \pm 0.4$ & $16.8 \pm 0.5$ \\
B & $1.63 \pm 0.06$ & $1.54 \pm 0.04$ & $1.67 \pm 0.05$ \\
\hline
\end{tabular}

\section{CONCLUSIONS}

The results obtained by ICP-SFMS for the U concentration were reasonably in accordance with the target values of $U$ provided by the PROCORAD 2010 urine samples, although the results obtained using ICP-QMS do not conform. Moreover, ICP-SFMS allows the quantification of isotopic ratios (and mass) of other minority isotopes contained in the sample. This study shows the utility of MS in the in vitro determination of long-lived radionuclides, both in routine or
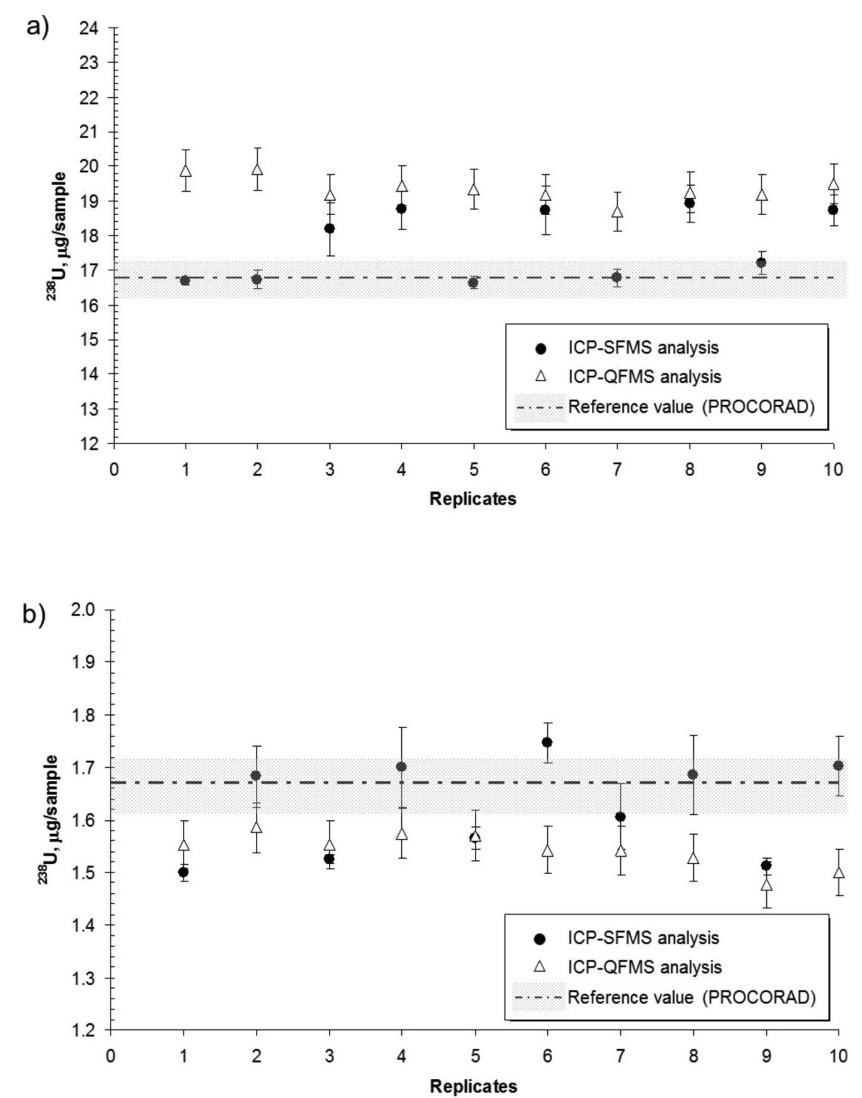

Figure 2. Analytical results for ${ }^{238} U$ measurements with ICP-SFMS and ICP-QMS normalized to the total volume of urine $(0.5 \mathrm{~L})$. a) Sample A; b) Sample $B$. The dotted line in the graphs indicates the target value, and the shaded area corresponds to the associated uncertainty

emergency situations, and their advantages versus classic techniques, such as AS (i.e., sample preparation, measurement time, sensitivity, and isotopic information). 


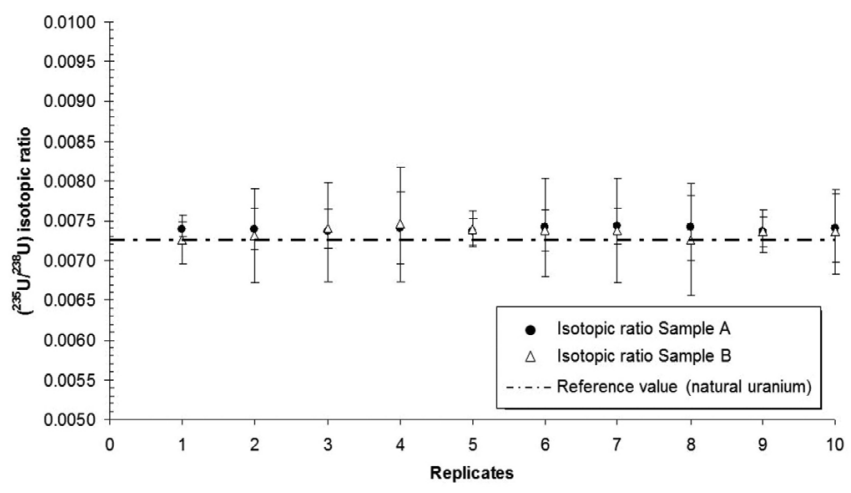

Figure 3. Results of isotopic ratio in the PROCORAD 2010 human urine samples measured by ICP-SFMS. A comparison with the natural isotopic ratio is also given in the figure

\section{ACKNOWLEDGEMENTS}

H. Hernández-Mendoza thanks Centro de Investigaciones Energéticas, Medioambientales y Tecnológicas (CIEMAT) for the FPI predoctoral fellowship. This work was supported by Projects CIEMAT 2007/P1423.

\section{REFERENCES}

1. Roth, P.; Höllriegl, V.; Werner, E.; Schramel, P.; Radiat. Prot. Dosim. 2003, 105, 157.

2. The Royal Society; The health hazards of depleted uranium munitions Part I. The Royal Society: London, 2001, p. 5-8.

3. Agency for Toxic Substances and Disease Registry (ATSDR); Toxicological profile for uranium. ATSDR, Atlanta Georgia, 2011, p. 14-25.
4. World Health Organization (WHO); Depleted Uranium, Sources, Exposure and Health Effects. WHO, Geneva, 2001, p. 1-3.

5. Bleise, A.; Danesi, P. R.; Burkar, W.; J. Environ. Radioact. 2003, 64, 93.

6. United Nations Scientific Committee on the Effects of Atomic Radiation (UNSCEAR); Sources and Effects of Ionizing Radiation, ANNEX B Exposures from natural radiation sources. United Nations, New York, 2000, p. 84-113.

7. Dang, H. S.; Pullat. V. R.; Pillai, K. C.; Health Phys. 1992, 62, 562.

8. Xiongxin. D.; Kramer-Tremblay, S.; Health Phys. 2011, 101, 144.

9. Xiongxin. D.; J. Radioanal. Nucl. Chem. 2011, 289, 595.

10. Hou. D.; Ross. P.; Anal. Chim. Acta. 2008, 608, 105.

11. Larivière. D.; Taylor. V. F.; Evans. R. D.; Cornett. R. J.; Spectrochim. Acta, Part B. 2006, 61, 877.

12. Becker. J. S.; Spectrochim. Acta, Part B. 2003, 58, 1757.

13. Perna. L.; Doctoral Thesis, Universitat Politècnica de Catalunya. Departament d'Enginyeria Química, 2003.

14. Zoriy. M.; Doctoral Thesis, Berichte des Forschungszentrums Jülich, 2005.

15. Becker, J. S.; Inorganic Mass Spectrometry: Principles and Applications, John Wiley \& Sons Ltd: Chichester, 2008, chap. 3.

16. Jakubowski, N.; Prohaska, T.; Rottmann. L.; Vanhaecke. F.; J. Anal. At. Spectrom. 2011, 26, 693

17. Jakubowski, N,; Prohaska. T.; Vanhaecke. F.; Roos. P. H.; Lindemann, T.; J. Anal. At. Spectrom. 2011, 26,727

18. Hernández-Mendoza. H.; Doctoral Thesis, Univesidad Complutense de Madrid, 2011.

19. Becker. J. S.; J. Anal. At. Spectrom. 2005, 20, 1173.

20. Parrish. R. R.; Thirlwall. M.; Pickford, C.; Horstwood, M. S. A.; Gerdes. A.; Anderson, J.; Coggon, D.; Health Phys. 2006, 90, 127.

21. Berard. P.; Montegue, A.; Briot, F.; Harduin. J.-C.; Radiat. Prot. Dosim. 2003, 105, 447. 